\title{
EXPLORING DEMOGRAPHIC INFLUENCES ON STUDENTS' ACADEMIC PERFORMANCE OVER A FIVE-YEAR PROGRAMME
}

\author{
T. Sommerville* \\ e-mail: sommer@ukzn.ac.za
}

\author{
V. S. Singaram* \\ e-mail: singaram@ukzn.ac.za
}

*Clinical and Professional Practice

School of Clinical Medicine

University of Kwa-Zulu Natal

Durban, South Africa

\section{ABSTRACT}

This mixed-method interpretive study examines the influence of five demographic characteristics or factors on the academic achievements of a cohort of 202 students through a five-year medical degree programme.

A quantitative analysis was performed, analysing a series of 32 summative assessments according to racial grouping (as defined in South Africa), first language, sex, age at entry, and source of finance for study. During the cohort's third year, interviews were conducted with a stratified sample of 19 students plus six staff members, individually or in groups. Their opinions on these five factors were elicited using, as stimuli for discussion, graphs showing the performance of a previous cohort.

Quantitative analysis of assessment marks demonstrated statistical differences between groups of students when examined according to race, first language, or financial support, the differences being maintained over the full five years. No significant differences were seen according to sex or age. Qualitative investigation revealed a number of opinions on, and explanations of, the differences observed. Some respondents' comments and proposed explanations seemed, at first, counterintuitive, yet appropriate to the pertaining circumstances.

This study has implications for academic development, and advances the literature on diversity, and demographic factors influencing student achievement, beyond mere statistics by exploring the details of students' lives as they relate to the factors investigated.

Keywords: diversity, higher education, quantitative methods, qualitative methods, student race, language, sex, age, finance

\section{INTRODUCTION}

"Student success can never be guaranteed. However, if lecturers, students and administrators make the effort to develop a common understanding of the factors that contribute to 
students' academic success, they will make important progress towards that important goal.” (Fraser and Killen 2005, 37).

A number of studies of influences on various academic success have been conducted (Breier and Wildschut 2006; Christie, Butler and Potterton 2007; Fleisch 2008; Leach and Moon 2008; Zeleza and Olekoshi 2004; Coleman 1966). The effects of learners’ gender, age, ethnicity, language, culture, socioeconomic status and health, and of schools' leadership, ethos, staffing and physical resources, have been noted over a span of years and a range of countries, from Coleman's (1966) classic study of school children in the USA to a study by Kusurkar et al. (2010) of medical students in Holland.

Students' academic achievements appear to be influenced by a number of features. Fraser and Killen (2005) and, separately, Ngidi (2007) conducted similar studies at three universities in South Africa. They found some concordance between students and lecturers on factors that were perceived to contribute to students' academic success. At the two contact universities, aspects of motivation and application constituted six of the top ten items identified by students and lecturers. General academic ability was ranked relatively low: students rated it $33^{\text {rd }}$ and lecturers $29^{\text {th }}$ of 34 items.

The authors of these two studies comment on the discordance between students and lecturers concerning contributors to success or failure in higher education. We find it interesting that items thought to be significant were generally not cognitive. This implies that students' backgrounds may be important with regard to their engagement in higher education, and thus their academic achievement.

The purpose of this study was to explore the magnitude and extent over time of noncognitive demographic characteristics that may be influential, as well as the nature of those influences, in the academic progress of medical undergraduates. As our theoretical framework, we have regarded these demographics as one part of the forces (biographical, contextual, institutional, programmatic) acting on the developing professional (Samuel 2008). We are aware of the changes in perceptions and the broadening and increasing inclusivity developing elsewhere in higher education (Berrey 2011; David 2007). These widespread developments provide a broader context for this study beyond the problematic nature of diversity in the South African setting (Cross 2004). Some of the advantages of deliberately engineered diversity amongst learning groups have been described previously (Singaram, Sommerville, Van der Vleuten and Dolmans 2011). In this article we wish to explore individual components of that diversity. We investigate the four characteristics (race, language, sex, age) according to which students in the learning groups were mixed, plus that of financial support, which is seen as a 
significant influence on education in South Africa at present. Rather than examine students' academic achievements in a single snapshot at one point, we have traced their course over the whole of their undergraduate careers, enabling us to chart possible changes in relationships over time. We hope thereby to provide a better understanding of which demographic characteristics, in a highly selected tertiary student population, may be advantageous or disadvantageous, and why.

The literature on demographic factors that may influence academic achievement is based largely on school populations, and relies chiefly on single cross-sectional observations rather than extended follow-through. The weight of the quantitative data available is not matched by explanations given by those under study. In this article we describe the methodology used to examine a number of these factors as they pertain to our students. The statistical method employed to compare aspects of each factor is described. Together with the results of the statistical comparisons, the responses of students and staff members to these factors are presented, and the interplay of statistics and perceptions is discussed relative to the literature.

\section{METHODOLOGY}

Employing an interpretive paradigm, we adopted a complementary (Greene, Caracelli and Graham 1989) mixed-method approach, using quantitative methods to delineate which demographic factors were influential individually, and qualitative methods to illuminate why this might be so. Institutional ethics approval, gatekeepers' permission, and respondents' written informed consent were obtained.

\section{Quantitative}

We recorded the assessment marks of a cohort of medical students for the five years of their MBChB programme. To enable direct comparisons, we followed only those students who progressed with the cohort; students who dropped out or failed a year were not followed after leaving the cohort under study. Similarly, those who had failed a year ahead of this cohort and dropped back into the cohort were not included in the analysis. Students' marks were analysed in terms of various demographic parameters available to us through the records of the University of KwaZulu-Natal (UKZN). The data gathered comprised "race” (black / white / Indian / "coloured"), first language, sex, age at the start of the course, and source of finance (self or family / scholarship or bursary / support from NSFAS (2015)).

Data were entered into MS Excel ${ }^{\circledR}$ spreadsheets, collated, coded for anonymity, then transferred to IBM SPSS ${ }^{\circledR}$. For initial analysis, we used a general linear model (GLM). This resembles analysis of variance (ANOVA) using regression (Field 2009), and represents an 
encompassing term that includes various comparative statistical tests (e.g. t test, ANOVA, regression analysis). Its advantage is the ability to incorporate matrices representing data sets and to make numerous comparisons (Trochim 2006). In our study, the data set of each student who completed the five-year programme had 32 assessment marks, which were examined in the light of each demographic characteristic. Because students who failed a year were not followed further, they had fewer than 32 marks.

\section{Qualitative}

When the cohort being studied was in its third year, we interviewed a purposive sample of 19 students representative of the cohort's demographics. The students were interviewed in a group of eight, a group of five, two pairs, and three individuals. As prompts for discussion, we used graphs that depicted previous students' performance in relation to several demographic characteristics. We interviewed individually six lecturers representing pre-clinical and clinical sciences, and they were asked for comments on the same graphs. The interviews were recorded, transcribed, and returned to interviewees for comments, additions, or corrections. They were then anonymously coded and analysed using NVivo ${ }^{\circledR}$ to search for themes which were then grouped for further analysis.

\section{RESULTS AND DISCUSSION}

Data were gathered from a cohort $(n=202)$ of medical students who were tracked from their first to fifth year. Of this cohort, 144 (72\%) successfully completed their medical degree in the standard five years. We present the descriptive statistics, graphical depictions, respondents' comments, and reflections on the demographic factors explored in this article. Respondents are identified by pseudonyms that indicate their ethnicity. Students are referred to by first names, staff members as "Dr [Surname]”.

\section{"Race"}

In the cohort studied, there were 112 black African, 70 Indian, 11 white and 9 coloured students. When examined in isolation, students' race was a significant influence on their test results (Figure 1).

The graph does not clearly distinguish, but the GLM shows significant $(p>0.001)$ differences between the four groups, chiefly between the Black and Indian groups (post-hoc testing; Bonferroni). Indian and white students' marks tended to lie higher than those of black and coloured students, although it is encouraging that the gap between the two groupings tended to narrow as the students progressed into the senior years. 


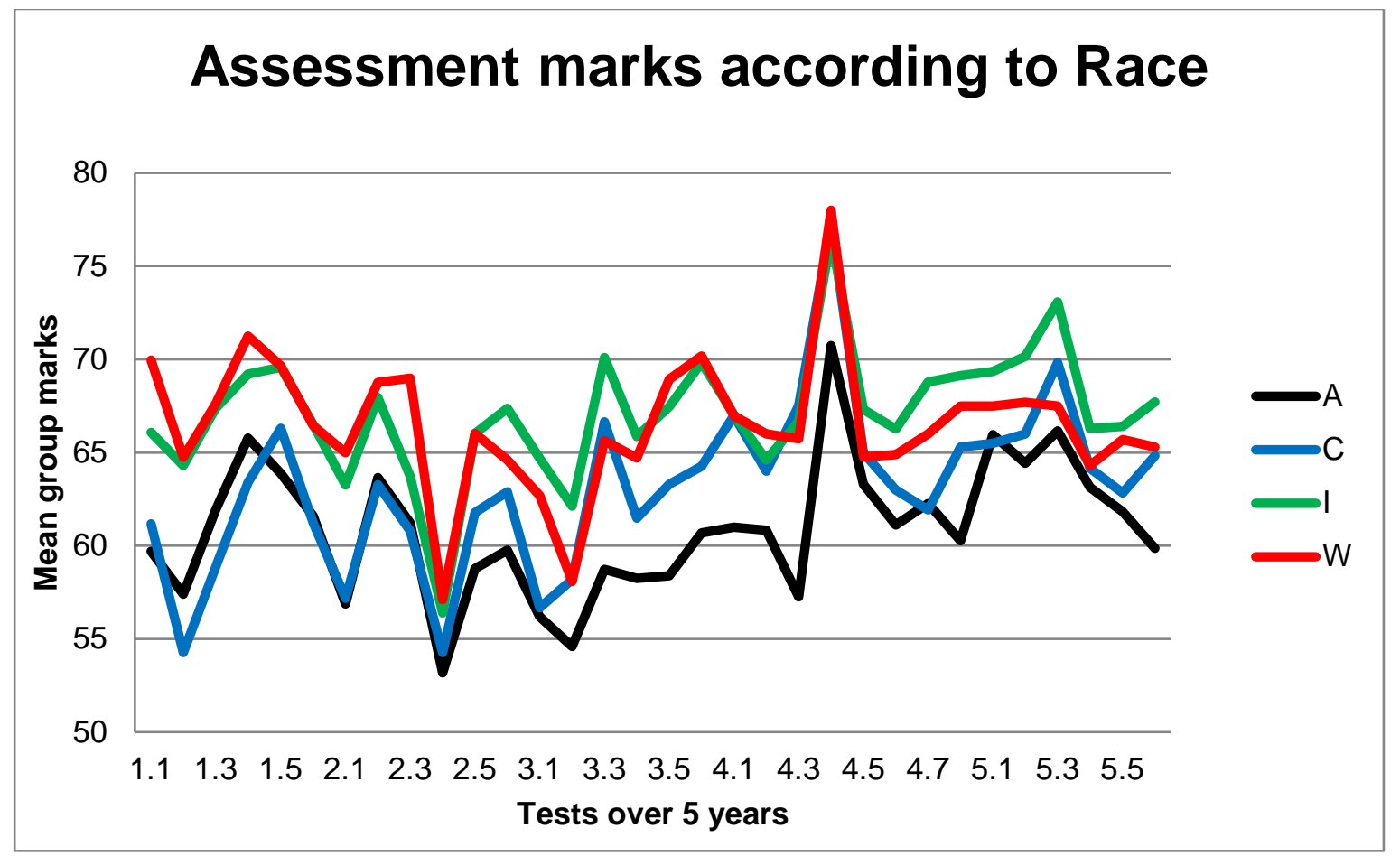

A = Black African; C = Coloured $; \mathrm{I}=$ Indian; $\mathrm{W}=$ White

Axes: $\quad \boldsymbol{x}$ : Consecutive assessment marks from $1^{\text {st }}$ to $5^{\text {th }}$ year

$\boldsymbol{y}$ : Average group marks (\%) for each assessment

Figure 1: Assessment results over five years according to students' race

As one might anticipate in the post-apartheid era, the students and their teachers made copious comments about the seeming racial differences in marks. They ascribed these differences to South Africa’s unequal allocation of resources to primary and secondary education.

"Well - who were the people most affected by apartheid? Those two groups. [African and coloured?] Definitely. They were the most dispossessed. [So you think this is a wash-over effect still?] Definitely. [After all those years?] Absolutely.” (Kevin)

That race itself gave rise to the differences in the graphs was universally rejected.

"[Y]ou have such a mixed group of people, you know, and, um - ja, mixed group of people from different backgrounds, with different ambitions in life, and we're like twenty-first century now, thinking modern I think, and - I don't know - I just don't see what I see here [in the graph] being reflected in the class that we have.” (Osane)

Dr. Hlubi, rejecting "disadvantage” as an explanation, ascribed different achievement in assessments to different extents of academic effort, granting that Africans have more socioeconomic difficulties than others. 
“I think - um - it is to do with perhaps motivation, or hard work - um - I don't think it has to do with disadvantage. ... I know that there are students who have issues: financial issues; they've got problems at home, family problems at home and all that, and that tends to happen [more] with African students - [Mm] - than white and Indian students.” (Dr Hlubi)

Susan raised comparable issues.

"[Indian and white students] tend to have less responsibilities because they're more well off, and other students might have a lot more on their plates than anyone in those other two lines.” (Susan)

Ahmed suggested that one's childhood background might play a role, while Zodwa and Susan suggested that background affects one’s thinking.

"I think like everyone has that ability to develop normally - you know, like - this, it's rather, rather than it's because of the race that you're getting these graphs, it's because of how you're influenced from small. Maybe there's some environmental factors.” (Ahmed)

"I've been around white families and they let their children really think abstract and not just think [gesture] 'box' - this is the box and this is how far the box goes; you can't open the box; it can't be flat - it's just a box; it's made to carry stuff; you can't do anything more than with a box. You're not taught to think beyond what the box can do for you." (Zodwa)

"It's not the schooling; it's even from back home - how you're taught how to think - [OK] and how to see things." (Susan)

Lungi’s experience of a comparatively resource-rich school but poor support at home revealed similar issues.

"And in terms of socioeconomic - ja, we were all staying in Durban North, we could all afford the Model C school, we were all dressing the same, but when you go back home, we weren't living the same lifestyle. It still goes back to that. Even though I could afford that, but my parents still didn’t know anything and couldn’t assist me with anything.” (Lungi)

"Race” as an influence on these students' academic achievement has been discussed elsewhere (Sommerville 2013). The racial proportions in the cohort we studied result from the medical faculty's deliberate selection of students according to a quota method of representing community demographics, rather than of rewarding academic performance alone (University of KwaZulu-Natal 2012). Such a method ensures, as a side-effect, that numerically larger groups include a broader range of abilities, leading in turn to a broader range of marks. We share Osane's hope that with the passage of time will come improved schooling and as succeeding generations gain readier access to education, differences between groups will be eliminated. 


\section{Language}

In total, 15 languages were spoken in this cohort. English was the first language of 91 students, while isiZulu (65) was the next most prevalent. Comparing all the students' first languages separately showed no obvious pattern. Statistical analysis confirmed this (ANOVA $p=0.145$ ). However, grouping the marks of other first-language speakers and of English first-language speakers, and comparing the two groups (Figure 2), displayed a difference that was significant $(p<0.001)$.

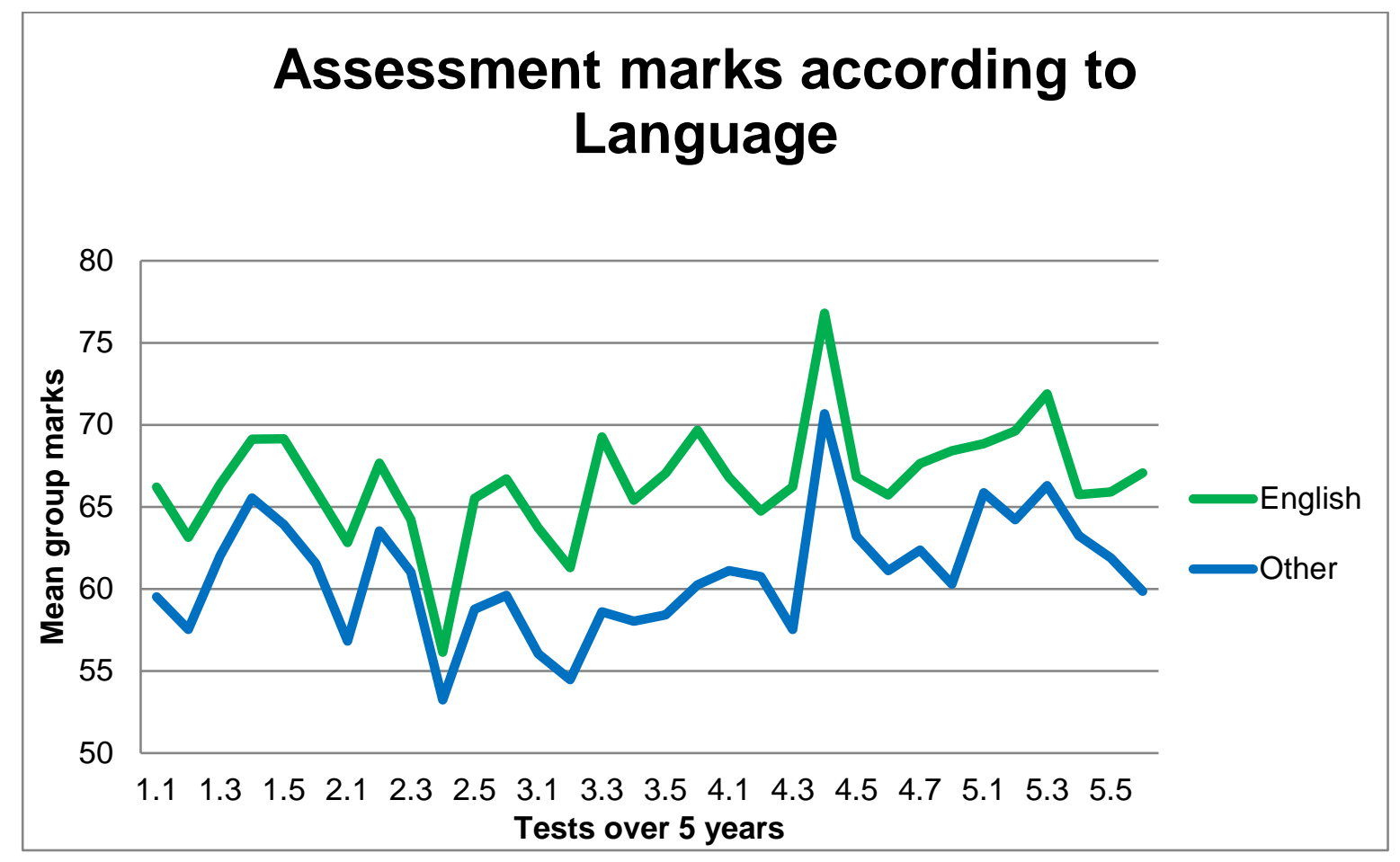

English = English first-language speakers

Other = English second-language speakers

Axes as in Figure 1

Figure 2: Assessment results over five years according to students' first language

If the language of teaching and learning coincides with the student's home language, one might expect this to be an advantage. Those who were second-language English speakers were aware of their linguistic disadvantage - but thought this challenge could be overcome.

"I know with some things, if I'm explaining - if we're chatting, we get to a point where you have to say it in Zulu because it will make more sense, as opposed to explaining it in English. So I think that is still there. It's not the major contributing factor but I think that that is definitely still there.” (Lungi)

"[W]hen they present to me; they'll throw in a few Zulu words when they're telling me what case is to be presented, but in the tutorial they remain in one language: in English.” (Dr Hlubi) 
Recognising that command of a second language is difficult in itself, and that expressing new concepts in that second language adds further complexity, respondents did not accept the suggestion of rendering the programme in their mother tongues.

“I honestly wouldn't write a paper in Zulu. Zulu is a very difficult - it's easy to talk but difficult to write. English is a lot simpler, honestly speaking.” (Lungi)

We suggest, following Bernstein (1996), that problems with language are different from problems with medical terminology, in the sense that language has to do with different segments of "horizontal discourse" - meaning different repertoires of expression - whereas medical terminology represents a separate "vertical discourse”. The term "horizontal discourse” implies that everyday idioms form separate segments, meaningless to members of diverse communities who do not share the same communicative repertoire. Bernstein $(1999,160)$ could have been writing about education under apartheid: "Clearly, the more members are isolated or excluded from each other, the weaker the social base for the development of either repertoire or reservoir.” Fluency in basic communication (horizontal discourse) does not ensure expertise in academic language (vertical discourse), but incapacity in the former may likely impede ability in the latter.

Despite its potential benefits for themselves and their patients, respondents advanced several motives for not choosing isiZulu as a language of instruction. These included difficulty in translating concepts, unobtainability of textbooks, plus being accustomed to English as language of instruction, awareness of its international use in communication, and the fact that students from other language backgrounds may not understand isiZulu. A further confounder was the practical inability of many Zulu speakers to use “correct” isiZulu. Similar findings in the literature echo these perceptions (Obanya 1995; Heugh 2009).

\section{Sex}

In the cohort studied, the majority (112) were female students. Across the 32 tests, females appeared to dominate academically, except on two occasions (Figure 3). However, there was no statistical difference $(p=0.347)$ between the two sets of results. Staff respondents generally referred to female students being more diligent than males.

"I've seen in the clinical years that women tend to be a little better at preparing for a tutorial and there seems to be a better organisation; and also I've noticed that more and more female students are group representatives. ... In terms of answering questions - displaying that they have read females are a little bit better ....” (Dr Hlubi) 


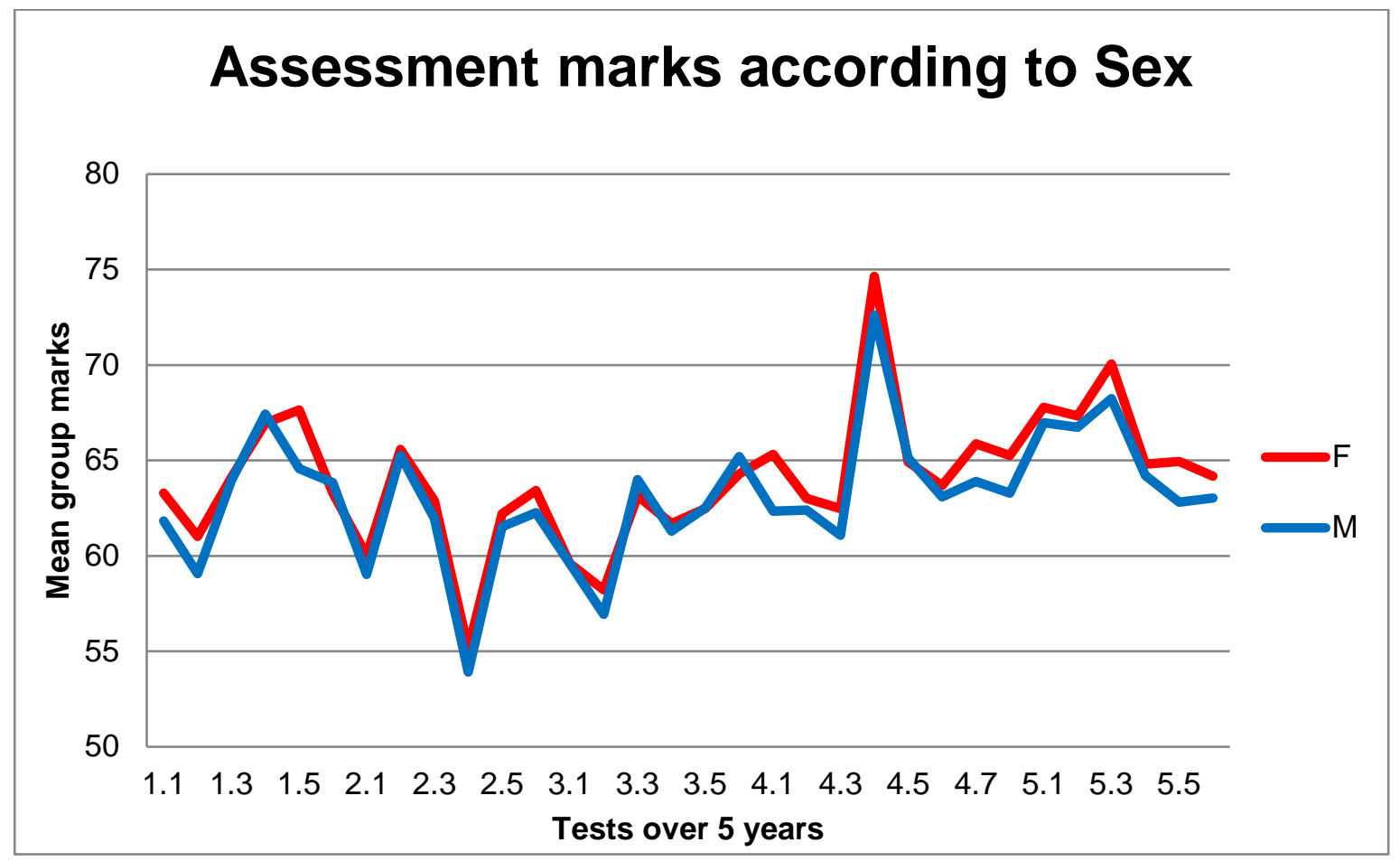

$\mathrm{F}=$ Female; $\mathrm{M}=$ Male

Axes as in Figure 1

Figure 3: Assessment results over five years according to students' sex

Student respondents generally tended to confirm the idea that females were more conscientious, and suggested several reasons for this: greater emotional maturity, diminished risk-taking, more organized lifestyles, and viewpoints better aligned with a vocation of caring.

“... they are more diligent, that's true ... They're more mature, isn't it? But then you'd expect that the mature students should do better, but females are generally three to four years ahead of their male counterparts.” (Kevin)

“Guys drink more - risky behaviour.” (Krish)

"Ah - ladies are very vulnerable and stuff like that, and I think if one relates to the field with passion and the intellect, then you care about the kids and helping people.” (Imbali)

Respondent were not surprised that females' test marks tended to be higher than males, and suggested various contributory reasons for this. These reflections are consistent with those in other studies (Haist, Wilson, Elam, Blue and Fosson 2000; Ferguson, James and Madeley 2002).

\section{Age}

The age of the class at the start of their course ranged from 17 to 33 years, the modal value being 18. Dividing the cohort on either side of the median (19.4 years) showed an interesting 
pattern (Figure 4), which overall was not statistically significant $(p=0.947)$.

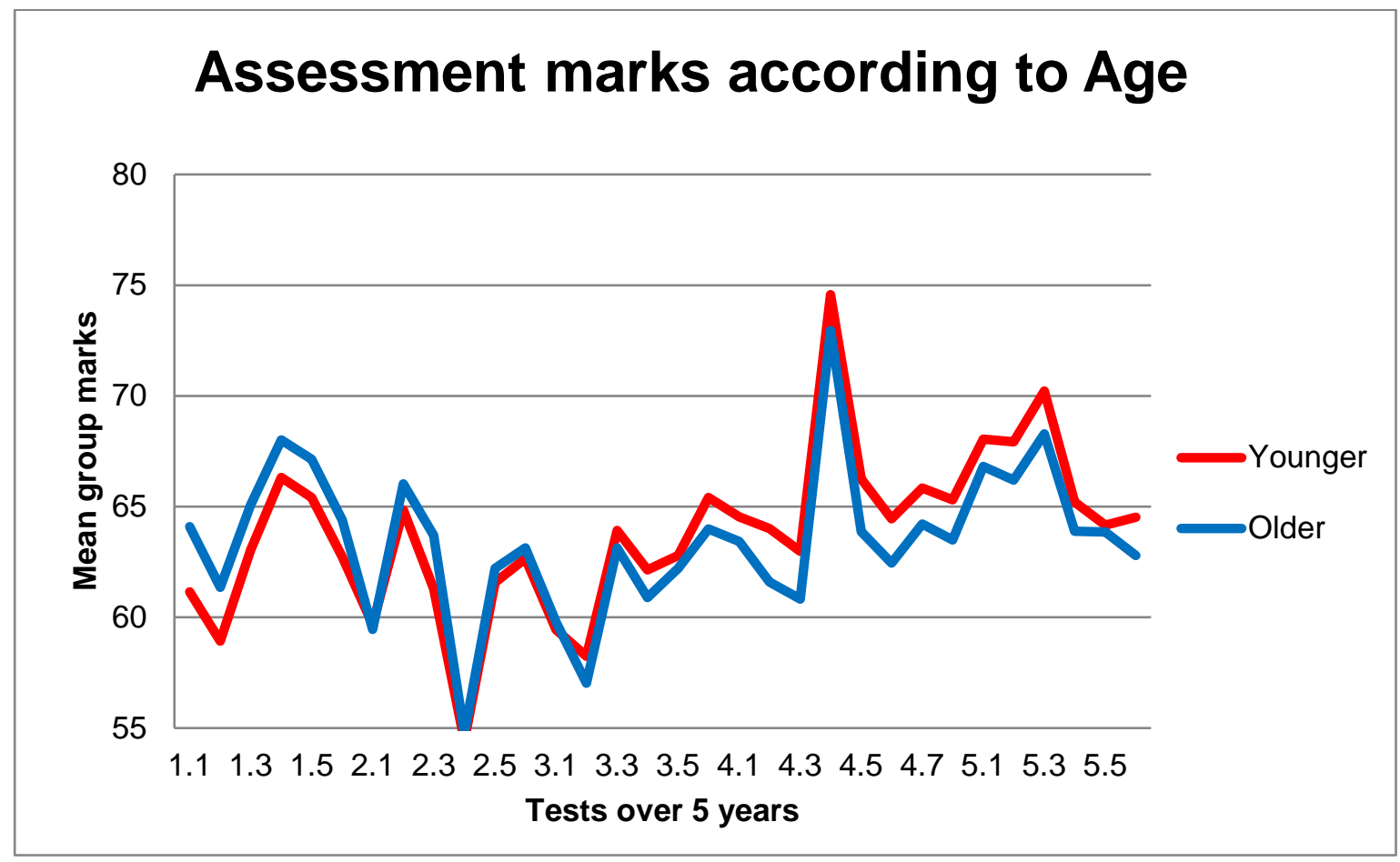

Younger $=17-19.4$ years; Older $=19.4-33$ years

Axes as in Figure 1

Figure 4: Assessment results over five years according to student age in $1^{\text {st }}$ year (2007)

Age might be expected to be a positive influence; indeed, in the first one-and-a-half years, the older students appeared to perform better, whereas from the middle of the $3^{\text {rd }}$ year that initial advantage disappeared. Some of the older students did feel at an advantage compared to schoolleavers.

“... kids these days in matric are way too young and they don't have the necessary background to get them through. I think that’s why most people struggle.” (Lungi)

Age and prior experience in higher education tend to go together, so it is unsurprising that previous studies (Haist et al. 2000; Ferguson et al. 2002; Trueman and Hartley 1996) have found it difficult to distinguish between these factors as influences on academic performance. This raises the question of whether the greater academic experience or the greater maturity of older students was a larger contributor to academic success.

\section{FINANCIAL SUPPORT}

Students' financial resources and constraints are an obvious, and very topical, influence on their 
academic performance. In their $1^{\text {st }}$ year, 85 students received merit-based scholarships or bursaries and another 19 were funded by NSFAS loans based on their financial need (Figure 5).

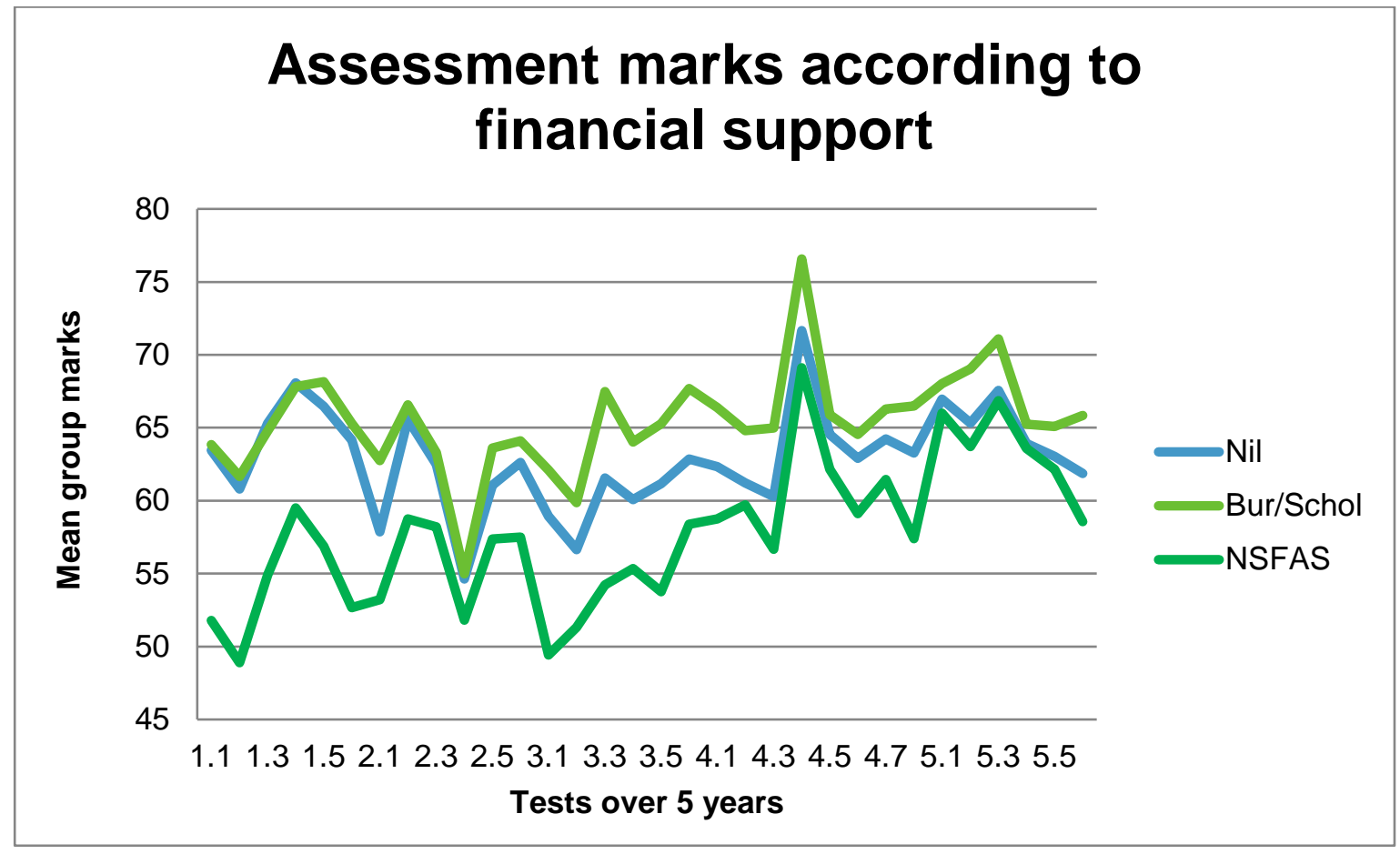

Nil = No financial support

Bur/Schol = Academic bursary/scholarship

NSFAS = Loan

Axes as in Figure 1

Figure 5: Assessment marks over five years according to level of financial support

There was a statistically significant $(p=0.001)$ difference between the marks of students without external financial aid and those on NSFAS loans.

Students with bursaries or scholarships might be expected to do better than the other two groups, since their awards were on the basis of academic merit. On the other hand, both resources and pressure to achieve arising from their families might be greater for students receiving no institutional financial support. As Krish explained, compared to poorer students with financial aid and living in university residences, more affluent students living at home under their parents' watchful eyes might as a result have achieved better marks than the former.

“But still they have a lot more freedom as well, because they're away from home. They don't have their parents to - well, not living under the roofs of their parents - have them tell them what to do - monitor them.” (Krish) 
The five diversity factors discussed here have been shown in other circumstances to affect learners' intellectual achievements, in and of themselves, and to confer significant advantages and corresponding disadvantages on students exhibiting different aspects of these factors. Our contention is that the majority of research has been conducted in primary and secondary schools, in which learners exhibit the whole gamut of conditions pertaining in society and thus display not only the average positions on various demographic scales but also the extremes that make for measurable differences. Medical students, in contrast, are an elite group; they are among the most carefully chosen students. As well as the painstakingly deliberate selection for admission to medical school, a selection-by-survival process has produced, out of high school, those individuals who have triumphed over the adversities active in their lives.

Race, language, sex, age and financial status are generally perceived, and have been measured, to be significant, and sometimes crippling, issues for learners. We are aware of the stresses associated with the study of medicine, and suggest that this study be duplicated in other disciplines' programmes and in other institutions of higher education to verify the influence of these factors on academic progression.

\section{CONCLUSION}

An extensive body of literature documents a variety of non-cognitive influences on academic performance. These remain inferences rather than reasons substantiated by interaction with those studied.

In our study, statistical analysis of numerical data essentially confirms what has been documented elsewhere: students with perceptible disadvantages tend to do less well than their more fortunate peers - whether the disadvantage is perceived in racial, linguistic, or financial terms. We have also demonstrated the longevity of these effects. Furthermore, by adopting a complementary mixed methods approach, we found that the corresponding interview data clarify the dynamics operating in the lives of the students concerned, and help explain the underlying forces that give rise to the statistics. This article highlights that behind the statistics lies a network of interactive factors rather than a single causative explanation. These findings have implications for curriculum development, student selection and throughput in higher education.

We do not argue in favour of specific support for racial, linguistic and financial "deficits” - an oft-heard and simplistic response. We present the insight that a degree of analytical complexity may be necessary when investigating the numerous elements of a multifactorial concept such as academic achievement. As Samuel (2008) pointed out in an analogous context, student characteristics constitute but one of several forces acting to shape the professional-in- 
training. One would do well to concentrate on those exerting a significant effect independent of other factors, which we are exploring in further studies. It is not yet clear whether educational policy on access, redress and transformation of academe should shift its focus from the intuitively obvious factors to those that might be revealed by complex methodologies. We would, however, expect similar studies in other higher education settings to yield similar results, since all the students in the field are subject to selection criteria. We consider that this study's findings are reproducible, despite the limitations of following only one cohort of students and interviewing a small number of that cohort. It would be salutary to repeat the study elsewhere in the sphere of health science education in order to confirm our results and broaden their applicability. Broadening the scope of the study by including factors other than those to which we had ready access would be a further recommendation. Mwamwenda's (1995) assertion that, under comparable circumstances, no differences are found between races is perhaps pivotal. While numerous assertions have been made about associations between race/ethnicity - or other non-cognitive characteristics - and academic performance, how does one ensure the ideal of "comparable conditions" in which to investigate the effect, for example, of race as distinct from culture, social circumstances and economics? (Even while using race as an example, we recognize that "race" is a much-contested concept, but acknowledge that much of South Africa's educational resources have previously and do still revolve around its dystopian use.) Analysis at another level - combining factors to reveal interactions and overlapping effects - may reveal that factors such as the five described here do not necessarily operate as independent influences on the test marks of the cohort under study.

We present a complementary mixed-method exploration of influences on academic achievement as an innovation in contrast to a purely quantitative analysis of single factors. We believe that this methodology yields a richness of insight and a depth of analysis that previous studies have not revealed. We see this article as a step, in the words of Fraser and Killen (2005, 37) towards "develop[ing] a common understanding of the factors that contribute to students' academic success”.

\section{REFERENCES}

Bernstein, B. 1996. Discourses, knowledge structures and fields: some arbitrary considerations. In: Pedagogy, symbolic control and identity: Theory, research, critique, ed. B. Bernstein, 169-181. London: Taylor \& Francis.

Bernstein, B. 1999. Vertical and horizontal discourse: An essay. British Journal of Sociology of Education 20(2): 157-173.

Berrey, E. C. 2011. Why diversity became orthodox in higher education, and how it changed the meaning of race on campus. Critical Sociology 37(5): 573-596.

Breier M. and A. Wildschut. 2006. Doctors in a divided society: The profession and education of 
medical practitioners in South Africa. Cape Town: HSRC Press.

Christie, P., D. Butler and M. Potterton. 2007. Schools that work. Pretoria: Ministry of Education report.

Coleman, J. S. 1966. Equality of educational opportunity. Washington: U.S. Department of Health, Education, and Welfare.

Cross, M. 2004. Institutionalising campus diversity in South African higher education: Review of diversity scholarship and diversity education. Higher Education 47: 387-410.

David, M. 2007. Equity and diversity: Towards a sociology of higher education for the twenty-first century? British Journal of Sociology of Education 28(5): 675-690.

Ferguson, E., D. James and L. Madeley. 2002. Factors associated with success in medical school: Systematic review of the literature. British Medical Journal 324: 952-957.

Field, A. 2009. Discovering statistics using SPSS. 3rd Edition. London: SAGE.

Fleisch, B. 2008. Primary education in crisis: Why South African schoolchildren underachieve in reading and mathematics. Cape Town: Juta.

Fraser, W. and R. Killen. 2005. The perceptions of students and lecturers of some factors affecting academic performance at two South African universities. Perspectives in Education 23(1): 25-40.

Greene, J. C., V. J. Caracelli and W. F. Graham. 1989. Toward a conceptual framework for mixedmethod evaluation designs. Educational Evaluation and Policy Analysis 11(3): 255-274.

Haist, S.A., J. F. Wilson, C. L. Elam, A. V. Blue and S. E. Fosson. 2000. The effect of gender and age on medical school performance: An important interaction. Advances in Health Science Education 5(3): 197-205.

Heugh, K. 2009. Contesting the monolingual practices of a bilingual to multilingual policy. English Teaching: Practice and Critique 8(2): 96-113.

Kusurkar, R., C. Kruitwagen, O. ten Cate and G. Croiset. 2010. Effects of age, gender and educational background on strength of motivation for medical school. Advances in Health Sciences Education 15(3): 303-313.

Leach, J. and B. Moon. 2008. The power of pedagogy. London: SAGE.

Mwamwenda, T. S. 1995. Educational psychology - an African perspective. Durban: Butterworth.

National Student Financial Aid Scheme. 2015. Mission Statement. https://www.nsfas.org.za/ NSFAS/ABOUT_US/MISSION_STATEMENT (Accessed 16 September 2015).

Ngidi, D. P. 2007. Students' and lecturers' perceptions of some factors influencing students' academic success or failure at a historically black university in South Africa. South African Journal of Higher Education 21(4): 717-732.

NSFAS see National Student Financial Aid Scheme.

Obanya, P. 1995. Case studies of curriculum innovations in western Africa. International Review of Education 41(5): 315-336.

Samuel, M. 2008. Accountability to whom? For what? Teacher identity and the Force Field Model of teacher development. Perspectives in Education 26(2): 3-16.

Singaram, V. S., T. E. Sommerville, C. P. M. van der Vleuten and D. H. J. M. Dolmans. 2011. "Looking at the glass half full": Exploring collaborative mixed group learning as a transformative force for social inclusion in a South African higher education setting. Alternation: International Journal for the Study of Southern African Literature and Languages 18(2): 96-114.

Sommerville, T. E. 2013. Race, power, performance and perception: Practical and theoretical observations in higher education at the University of KwaZulu-Natal. Alternation 20(1): 74-99.

Trochim, W. M. K. 2006. General linear model. Social Research Methods. http://www.socialresearch methods.net/kb/genlin.php (Accessed 1 December 2010).

Trueman, M. and J. Hartley. 1996. A comparison between the time-management skills and academic performance of mature and traditional-entry university students. Higher Education 32: 199-215. 
University of KwaZulu-Natal. 2012. Undergraduate prospectus. Durban \& Pietermaritzburg: Student Academic Administration.

Zeleza, P. T. and A. Olekoshi. 2004. African universities in the twenty-first century: Future challenges and a research agenda. In African Universities in the twenty-first century, ed. P. T. Zeleza and A. Olekoshi. Pretoria: Unisa Press. 